TAO, Vol. 16, No. 5, 1189-1204, December 2005

\title{
Validation of Satellite-Derived Sea Surface Temperatures for Waters around Taiwan
}

\author{
Ming-An Lee ${ }^{1,3}$, Yi Chang ${ }^{1, *}$, Futoki Sakaida ${ }^{2}$, Hiroshi Kawamura ${ }^{2}$, \\ Chao-Hsiung Cheng ${ }^{1}$, Jui-Wen Chan ${ }^{1,3}$, Iris Huang ${ }^{3}$
}

(Manuscript received 16 December 2004, in final form 9 August 2005)

\begin{abstract}
In order to validate the Advanced Very High Resolution Radiometer (AVHRR)-derived sea surface temperatures (SST) of the waters around Taiwan, we generated a match-up data set of 961 pairs, which included in situ SSTs and concurrent AVHRR measurements for the period of 1998 to 2002. Availability of cloud-free images, i.e., images with more than $85 \%$ of cloud-free area in their coverage, was about $2.23 \%$ of all AVHRR images during the study period. The range of in situ SSTs was from $10.5^{\circ} \mathrm{C}$ to $30.8^{\circ} \mathrm{C}$. The satellite derived-SSTs through MCSST and NLSST algorithms were linearly related to the in situ SSTs with correlation coefficients of 0.985 and 0.98 , respectively. The MCSSTs and NLSSTs had small biases of $0.009 \mathrm{C}^{\circ}$ and $0.256 \mathrm{C}^{\circ}$ with root mean square deviations of $0.64 \mathrm{C}^{\circ}$ and $0.801 \mathrm{C}^{\circ}$, respectively, therefore the AVHRR-based MCSSTs and NLSSTs had high accuracy in the seas around Taiwan.
\end{abstract}

(Key words: Sea surface temperature (SST), AVHRR-derived SST, Validation, Taiwan)

\section{INTRODUCTION}

Satellite imagery provides a wide view of the earth's surface with high-spatial and -temporal resolutions, and can be used efficiently to evaluate global and regional meteorological

\footnotetext{
${ }^{1}$ Department of Environmental Biology and Fisheries Science, National Taiwan Ocean University, Keelung, Taiwan, ROC

${ }^{2}$ Center for Atmospheric and Oceanic Studies, Faculty of Science, Tohoku University, Sendai, Japan

${ }^{3}$ Ocean Data Bank of National Center for Ocean Research, Taipei 106, Taiwan

* Corresponding author address: Prof. Ming-An Lee, Department of Environmental Biology and Fisheries Science, National Taiwan Ocean University, Keelung, Taiwan, ROC;

E-mail:malee@mail.ntou.edu.tw
} 
and oceanographic conditions. Among parameters derived from satellite remote sensing, sea surface temperature (SST) is one of the most basic oceanographic parameters associated with climate and weather systems. Fluxes of sensible heat, latent heat, and long-wave radiation are also critically dependent on the SST. SST variations are directly linked with atmospheric and oceanic variations with a variety of temporal and spatial scales. Satellite-derived SSTs are widely used in studying atmospheric and oceanic problems, including fisheries, meteorologi$\mathrm{cal} /$ oceanographic operational businesses, and oceanic environmental management. In waters around Taiwan, remotely sensed SSTs have been applied to oceanography and marine fishery since 1988 (Gong et al. 1992; Lin et al. 1992; Liao et al. 1997; Lee et al. 1999).

At present, the Advanced Very High Resolution Radiometer (AVHRR) on board NOAA polar-orbiting satellites is the most popular instrument for regional/global SST retrieval. It has been functioning for more than a quarter century since 1978 (Bernstein 1982). The AVHRR has three infrared channels at $3.5-3.9 \mu \mathrm{m}, 10.5-11.5 \mu \mathrm{m}$, and $11.5-12.5 \mu \mathrm{m}$, respectively. Several algorithms have been developed in the past to convert the AVHRR-measured infrared radiances into SST values (e.g., Barton 1995). The Multi-Channel Sea Surface Temperature (MCSST) algorithm was first developed for operational use (e.g., McMillin and Crosby 1984) before the nonlinear SST (NLSST) algorithm was developed to overcome some weaknesses in the MCSST algorithm (Walton 1988). Lately, the NOAA/NESDIS (National Environmental Satellite, Data and Information Service) has published and occasionally updated the coefficients of MCSST and NLSST algorithms for operational AVHRR SST retrieval (Li et al. 2001). Validations of MCSST products indicate that their root mean square (RMS) errors are less than $0.7^{\circ} \mathrm{C}$ against in situ SSTs for global oceans (e.g., Strong and McClain 1984; McClain et al 1985, Bates and Diaz 1991) and the seas around Japan (e.g., Sakaida and Kawamura 1992a, 1992b, 1996).

The MCSST and NLSST algorithms correct the atmospheric attenuation of the upcoming infrared radiation from the sea surface caused primarily by water vapor (Anding and Kauth 1970). Since NOAA coefficients are tuned against globally-distributed in situ SSTs observed by drifting buoys, estimated SSTs have rather high accuracy for the open ocean. In contrast, Sakaida and Kawamura (1992a, b) indicated that NOAA MCSST coefficients are not always applicable to the seas around Japan. Key et al. (1997) used an extensive validation analysis for the satellite-derived SSTs at high latitudes and pointed out that their larger errors were attributable to the spatially variable atmospheric/surface conditions of the validation area. Kawai and Kawamura (1997a) investigated the MCSST biases against the in situ SSTs in the seas around Japan, and found seasonal biases in the northern part of the Japan Sea and Sea of Okhotsk. These authors (Kawai and Kawamura 1997b) also examined MCSST positive biases in the Sea of Okhotsk in summer. They found that biases are attributable to sharp gradients in diurnal temperature profile formed close to sea surface. To understand the accuracy of satellite-derived SST, scientists have performed various validation efforts by comparing AVHRR measurements with moored buoys, drifting and ship measurements in the global oceans as well as in different coastal regions ( $\mathrm{Li}$ et al. 2001).

According Liao et al. (1997), the bias of satellite-derived SST around Taiwan against the in situ SST was about $0.21 \mathrm{C}^{\circ}$. However, a large RMS deviation of $4.14 \mathrm{C}^{\circ}$ was observed by the same authors in the SST range of 20 to $30^{\circ} \mathrm{C}$ in the southern East China Sea. The problem 
of the large RMS deviation by Liao et al. (1997) may be attributed to insufficient quality control in creating the match-up data set, which requires precise navigation, severe cloudscreening, and checking of abnormal satellite and in situ SSTs. Time-series of drift- and mooredbuoy data are generally lacking in the waters around Taiwan. Thus, quality control in creating a match-up data set is time-consuming because a large number of match-ups are required in order to obtain statistically significant results.

In this paper, AVHRR SSTs obtained by the MCSST and NLSST algorithms were examined and validated in the waters around Taiwan using the in situ SSTs archived at the National Center of Ocean Research (NCOR, Taiwan).

\section{DATA AND METHOD}

\subsection{Satellite SST Images and in situ Observations}

The High Resolution Picture Transmission (HRPT) data of the NOAA-12 16 were received and archived in the Department of Environmental Biology and Fisheries Science at National Taiwan Ocean University. The AVHRR images in the HRPT data were available at about four to six times daily during the period of January 1998 to December 2002. During the preprocessing of the data, satellite images were navigated (i.e., corrected for distortion and registered to a map) and nudged (i.e., entire image shifted to fit map overlap) to correct receiving system timing errors and/or satellite altitude errors. The ground resolution of the processed image was set to $1.1 \mathrm{~km}$. The navigation and cloud detection techniques used in this study were described in Sakaida and Kawamura (1992a).

The cloud-free images were further processed to obtain the MCSSTs and NLSSTs (Li et al. 2001) according to the following equations:

$$
\begin{aligned}
& \operatorname{MCSST}=\mathrm{A}_{1} \times \mathrm{T}_{4}+\mathrm{A}_{2} \times\left(\mathrm{T}_{4}-\mathrm{T}_{5}\right)+\mathrm{A}_{3} \times\left(\mathrm{T}_{4}-\mathrm{T}_{5}\right) \times(\operatorname{Sec} \theta-1)-\mathrm{A}_{4} \\
& \mathrm{NLSST}=\mathrm{B}_{1} \times \mathrm{T}_{4}+\mathrm{B}_{2} \times\left(\mathrm{T}_{4}-\mathrm{T}_{5}\right) \times \operatorname{MCSST}+\mathrm{B}_{3} \times\left(\mathrm{T}_{4}-\mathrm{T}_{5}\right) \times(\operatorname{Sec} \theta-1)-\mathrm{B}_{4},
\end{aligned}
$$

where $T_{4}$ and $T_{5}$ are the brightness temperatures of channels 4 and 5 in Kelvin, respectively; $\operatorname{Sec} \theta$ is the secant of the satellite zenith angle $\theta$. The constant coefficients $A_{1} \sim A_{4}$ and $B_{1} \sim B_{4}$ of each satellite are shown in Table 1.

The routinely-calibrated CTD (SBE21) data collected by R/V Ocean Researcher I, II, and III were used for comparison with the SST measurements. The CTD data were archived in the Ocean Data Bank (ODB), NCOR. Profiles of seawater temperature were constructed from the data collected by 102, 241 and 294 cruises onboard R/V Ocean Researcher I, II, and III, respectively, from January 1998 to November 2002 (Table 2). We have a total of 9083 data points (stations) of shipboard measurements in this study. During the survey, the seawater at the depth of less than $5 \mathrm{~m}$ was pumped up and then the sea surface temperature was measured by the respective sensor, while the longitude and latitude of the station were positioned by the GPS. 
Table 1. Coefficients of MCSST and NLSST algorithms.

\begin{tabular}{|c|c|c|c|c|c|c|c|c|}
\hline \multirow{2}{*}{ Satellite } & \multicolumn{2}{|c|}{ NOAA-12 } & \multicolumn{2}{c|}{ NOAA-14 } & \multicolumn{2}{c|}{ NOAA-15 } & \multicolumn{2}{c|}{ NOAA-16 } \\
\cline { 2 - 9 } Coefficients & Daytime & Nighttime & Daytime & Nighttime & Daytime & Nighttime & Daytime & Nighttime \\
\hline $\mathrm{A}_{1}$ & 0.963563 & 0.967077 & 1.017342 & 1.029088 & 0.964243 & 0.976789 & 0.999314 & 0.995103 \\
\hline $\mathrm{A}_{2}$ & 2.579211 & 2.384376 & 2.139588 & 2.275385 & 2.71296 & 2.77072 & 2.301950 & 2.53657 \\
\hline $\mathrm{A}_{3}$ & 0.242598 & 0.480788 & 0.779706 & 0.752567 & 0.387491 & 0.435832 & 0.628976 & 0.753281 \\
\hline $\mathrm{A}_{4}$ & 263.0060 & 263.940 & 278.4300 & 282.240 & 262.443 & 266.290 & 273.7680 & 273.146 \\
\hline $\mathrm{B}_{1}$ & 0.876992 & 0.888706 & 0.939813 & 0.933109 & 0.913116 & 0.922560 & 0.914471 & 0.898887 \\
\hline $\mathrm{B}_{3}$ & 0.083132 & 0.081646 & 0.076066 & 0.078095 & 0.0905762 & 0.0936114 & 0.077612 & 0.0839331 \\
\hline $\mathrm{B}_{3}$ & 0.349877 & 0.576136 & 0.801458 & 0.738128 & 0.476940 & 0.548055 & 0.668532 & 0.755283 \\
\hline $\mathrm{B}_{4}$ & 236.6670 & 240.229 & 255.1650 & 253.428 & 246.887 & 249.819 & 248.1160 & 244.006 \\
\hline
\end{tabular}

Table 2. The information of cruises from each research vessel during the study period.

\begin{tabular}{|c|c|c|c|}
\hline $\mathrm{R} / \mathrm{V}$ & Cruises Number & Date & Number of stations \\
\hline OR I & 102 & $1998 / 01 / 06 \sim 2002 / 11 / 29$ & 2164 \\
\hline OR II & 241 & $1998 / 04 / 18 \sim 2002 / 10 / 16$ & 4187 \\
\hline OR III & 294 & $1998 / 01 / 07 \sim 2002 / 11 / 30$ & 2732 \\
\hline
\end{tabular}

Stations used in the present study are shown in Fig. 1. The region was divided into four subdivisons: A) Kuroshio region; B) southern East China Sea; C) Taiwan Strait; and D) northern South China Sea. The geographic and oceanographic characteristics concerning these subdivisions are available from Xu and Oda (1999), Hu et al. (2000), Lin et al. (2000), Cho and Matsuoka (2001), and Jan et al. (2002).

\subsection{Match-up data set}

In order to compare the satellite-derived SSTs with the in situ SSTs, we produced pairs of co-located satellite and in situ SST observations with time difference shorter than 6 hours. The satellite observations have spatial averages of $3 \times 3$ pixels around each field survey location 


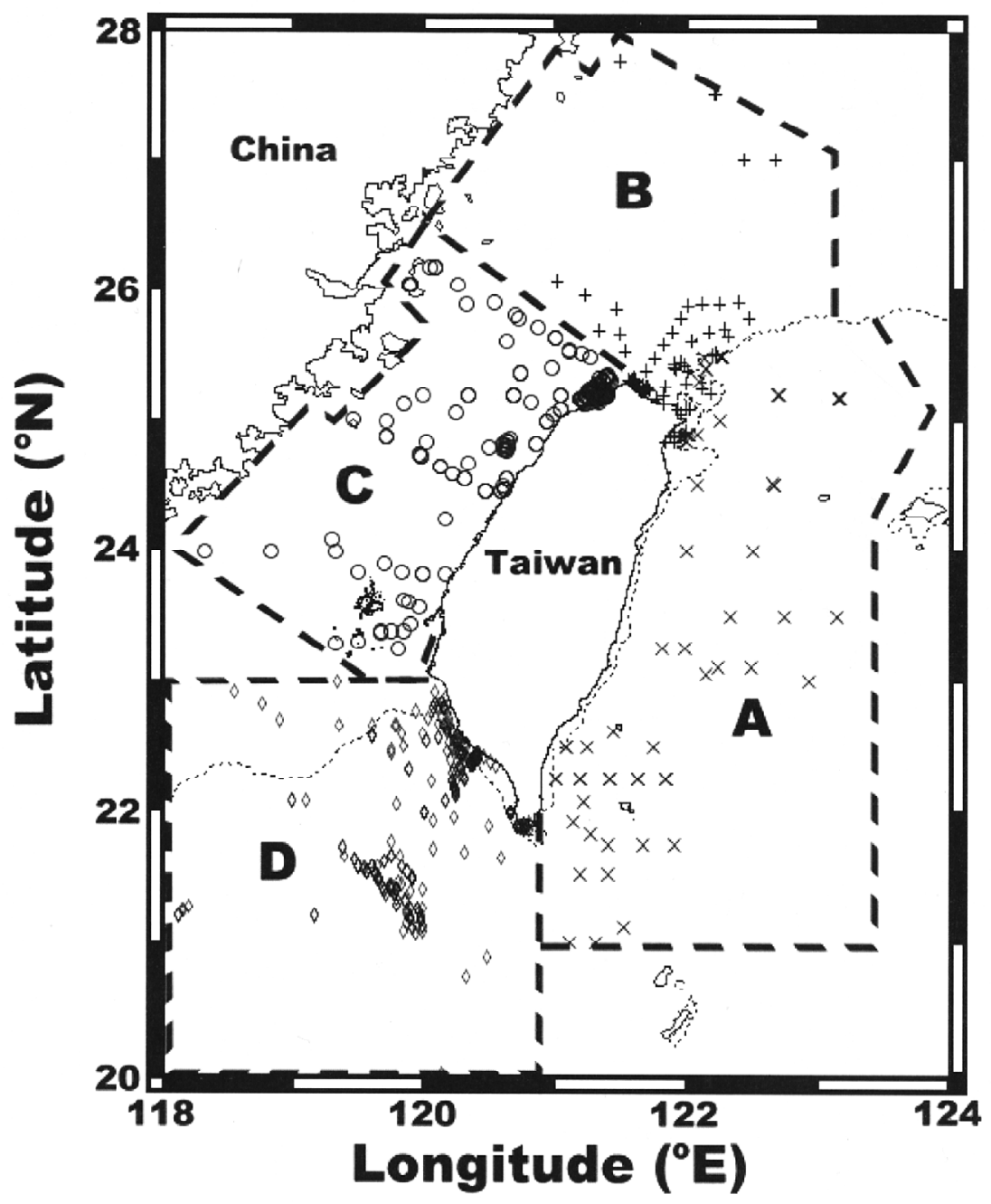

Fig. 1. Spatial distribution of the field CTD observation stations used in this study. A D: four subdivisions in the study area, i.e., A: the Kuroshio region, B: the southern East China Sea, C: the Taiwan Strait, and D: the northern South China Sea. Different symbols $(x,+, \diamond, 0)$ of CTD stations applied to different subdivisions. The solid line indicates the isopleth line of 200-meter depth.

(Sakaida and Kawamura 1992a). These procedures were described in Sakaida and Kawamura (1996) in detail. A total of 961 pairs were obtained, and their monthly numbers of pairs are shown in Table 3. There were 782 and 179 match-ups in the daytime and nighttime, respectively. 
Table 3. Monthly distribution of match-up data created in the study period.

\begin{tabular}{|c|c|c|c|c|c|c|c|c|c|c|c|c|}
\hline \multirow{2}{*}{ Year } & \multicolumn{2}{|c|}{1998} & \multicolumn{2}{|c|}{1999} & \multicolumn{2}{|c|}{2000} & \multicolumn{2}{c|}{2001} & \multicolumn{2}{c|}{2002} & \multicolumn{2}{c|}{ Total } \\
\cline { 2 - 16 } & Daytime & Nighttime & Daytime & Nighttime & Daytime & Nighttime & Daytime & Nighttime & Daytime & Nighttime & Daytime & Nighttime \\
\hline Jan & 0 & 0 & 0 & 5 & 40 & 0 & 0 & 0 & 0 & 0 & 40 & 5 \\
\hline Feb & 1 & 0 & 0 & 9 & 0 & 0 & 2 & 1 & 0 & 0 & 3 & 10 \\
\hline Mar & 0 & 0 & 19 & 11 & 55 & 0 & 35 & 13 & 0 & 0 & 109 & 24 \\
\hline Apr & 0 & 0 & 19 & 3 & 17 & 0 & 5 & 0 & 15 & 21 & 56 & 24 \\
\hline May & 9 & 4 & 15 & 15 & 2 & 0 & 0 & 0 & 21 & 9 & 47 & 28 \\
\hline Jun & 4 & 1 & 18 & 12 & 24 & 0 & 9 & 0 & 11 & 5 & 66 & 18 \\
\hline Jul & 3 & 0 & 8 & 2 & 18 & 0 & 20 & 0 & 33 & 5 & 82 & 7 \\
\hline Aug & 25 & 0 & 20 & 19 & 12 & 0 & 46 & 0 & 6 & 0 & 109 & 19 \\
\hline Sep & 7 & 0 & 36 & 18 & 42 & 9 & 8 & 0 & 9 & 11 & 102 & 38 \\
\hline Oct & 10 & 0 & 11 & 0 & 19 & 0 & 10 & 0 & 25 & 6 & 75 & 6 \\
\hline Nov & 17 & 0 & 10 & 0 & 11 & 0 & 17 & 0 & 0 & 0 & 55 & 0 \\
\hline Dec & 0 & 0 & 0 & 0 & 14 & 0 & 24 & 0 & 0 & 0 & 38 & 0 \\
\hline Total & 76 & 5 & 156 & 94 & 254 & 9 & 176 & 14 & 120 & 57 & 782 & 179 \\
\hline
\end{tabular}

\section{RESULTS}

\subsection{Cloud-free Image Availability}

A total number of 10524 passes of HRPTs is available during the period of January 1998 to December 2002 (Fig. 2). The monthly number of passes decreases significantly during three periods (March to April and August 1998, and March to April 2002) because of work on improvements of the receiving station at the National Taiwan Ocean University. Following Kubota (1994) and Sakaida and Kawamura (1996), a cloud-free image is defined as one that is cloud-free more than $85 \%$ of its coverage area. The monthly number of cloud-free images is shown in Fig. 2. The availability of AVHRR SSTs in cloud-free images was highly dependent on season; the maximum number of cloud-free images appeared in August 2001 and the minimum in September to December 1998. The cloud-free image availability rate was about $2.23 \%$. The number of cloud-free images in summer was about 22.2 images per season, which was significantly higher than that in spring (5.6 images), autumn (6.8), and winter (2.6), respectively. On average, users can get about one pass every 4 days in summertime in the waters around Taiwan, but about one pass per month in winter. 


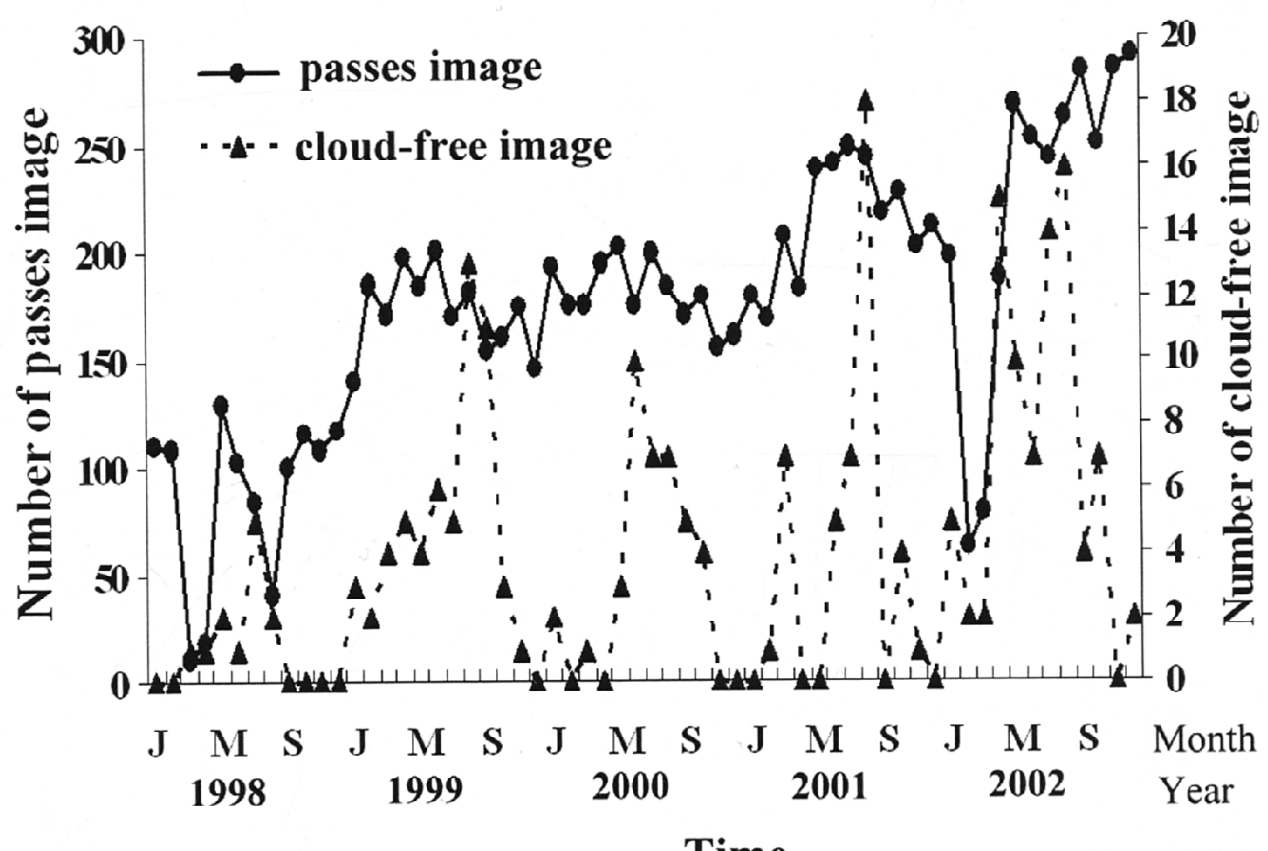

Time

Fig. 2. Monthly number of passes and cloud-free images for the study area.

\subsection{Characteristics of in situ SSTs in the Study Area}

Figure 3 shows the frequency distribution of the in situ SSTs used in the present study. It indicates that most SSTs were within the range between $23^{\circ} \mathrm{C}$ and $29^{\circ} \mathrm{C}$ though the full range was from $10^{\circ} \mathrm{C}$ to $31^{\circ} \mathrm{C}$. Table 4 shows statistics of the in situ SSTs in the four subdivisions, and Fig. 4 shows the seasonal mean and standard deviation for each subdivision shownin Fig. 1. The seasonal mean SSTs were always higher than $23^{\circ} \mathrm{C}$ with yearly standard deviations smaller than $1.7 \mathrm{C}^{\circ}$ in the open seas (subdivision $\mathrm{A}$ and $\mathrm{D}$ ). On the continental shelf (subdivision $\mathrm{B}$ and C), the SSTs range was from $10.5^{\circ} \mathrm{C}$ to $30.8^{\circ} \mathrm{C}$ (Fig. 3), with higher yearly standard deviation of $3.51 \mathrm{C}^{\circ}$ in $\mathrm{B}$ and $3.59 \mathrm{C}^{\circ}$ in $\mathrm{C}$ (Table 4). The mean SSTs in summer were $27^{\circ} \mathrm{C} \sim 29^{\circ} \mathrm{C}$ with standard deviations of less than $1.8 \mathrm{C}^{\circ}$ in all subdivisions. Differences in the SST fields between the open ocean and continental shelf were enhanced in winter (mean SSTs) and spring (standard deviations).

\subsection{Comparison of Satellite-derived and in situ SSTs}

MCSSTs and NLSSTs were compared with in situ SSTs (Figs. 5, 6). The comparison illustrated that MCSSTs and NLSSTs were linearly correlated with the in situ SSTs with correlation coefficients of 0.985 and 0.98 , respectively. Relative to the in situ SSTs, the MCSSTs 


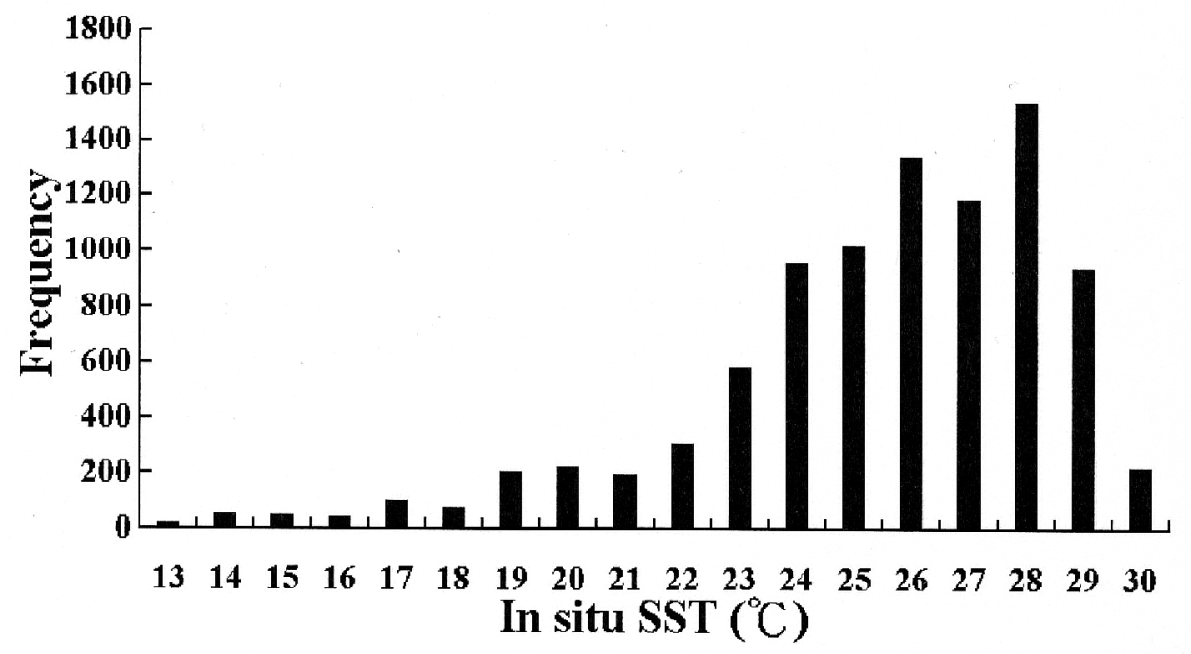

Fig. 3. Frequency distribution of the in situ SSTs in the study area.
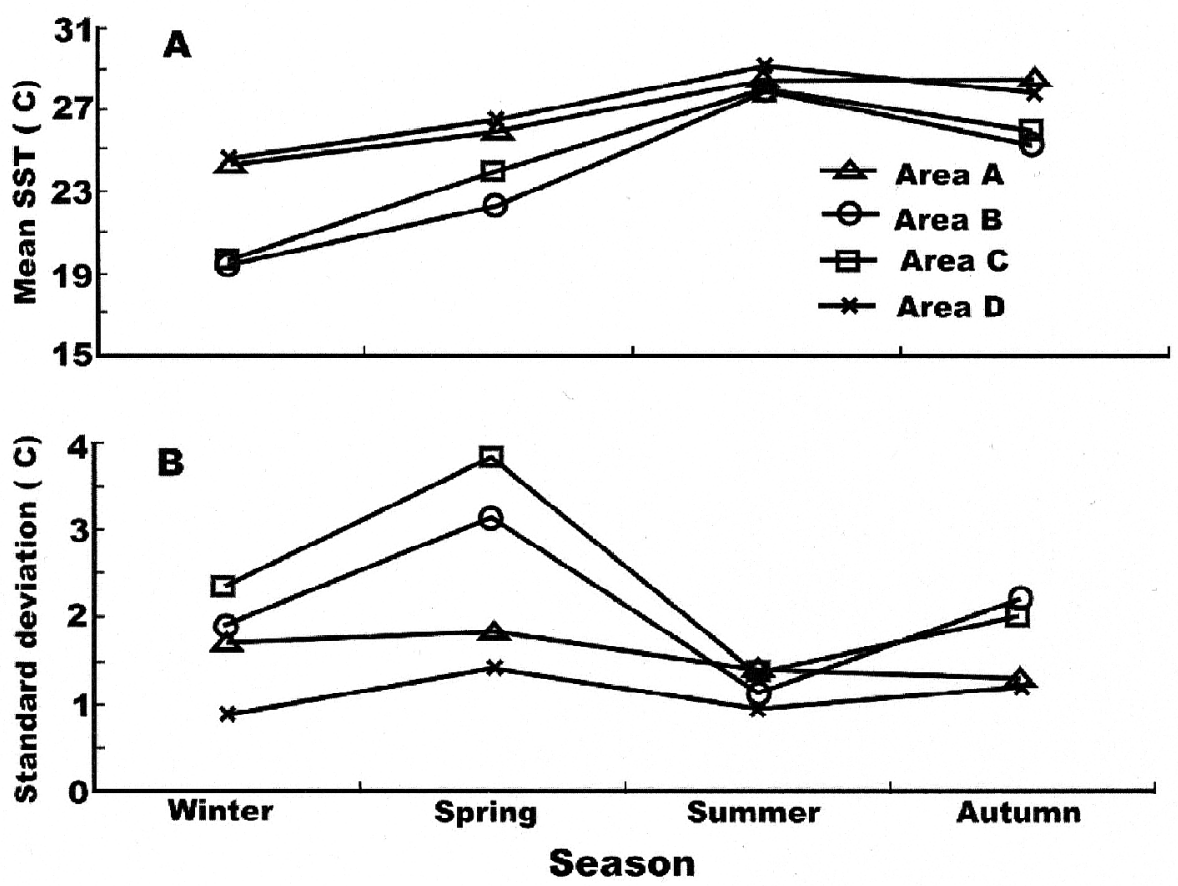

Fig. 4. Seasonal mean SST (A) and standard deviations (B) for each subdivision area during the period of January 1998 to December 2002. 
and NLSSTs had a bias (MCSST/NLSST minus in situ SST) of $0.009 \mathrm{C}^{\circ}$ and $0.256 \mathrm{C}^{\circ}$, respectively, and with RMS deviations of $0.64 \mathrm{C}^{\circ}$ and $0.801 \mathrm{C}^{\circ}$, respectively (Table 5). This implied that the MCSSTs algorithm produces slightly more accurate SST measurements than the NLSST algorithm in the waters around Taiwan.

Figure 7 demonstrates the differences between MCSSTs/NLSSTs and in situ SSTs in each month and each subdivision area. It is evident that, for the area D (northern South China Sea), the differences were large during the period from May to September and sometimes exceeded $\pm 3 \mathrm{C}^{\circ}$.

Table 4. Maximum and minimum in situ SSTs $\left({ }^{\circ} \mathrm{C}\right)$ and observation number for each subdivision area. Yearly mean and standard deviation of the in situ SSTs are also shown.

\begin{tabular}{|c|c|c|c|c|c|}
\hline Subdivision & $\begin{array}{c}\text { Minimum } \\
\text { SST }\end{array}$ & $\begin{array}{c}\text { Maximum } \\
\text { SST }\end{array}$ & $\begin{array}{c}\text { Mean } \\
\text { SST }\end{array}$ & $\begin{array}{c}\text { Standard } \\
\text { Deviation }\end{array}$ & No. of observations \\
\hline A & 19.30 & 31.06 & 27.46 & 1.99 & 3208 \\
\hline B & 11.33 & 30.82 & 24.74 & 3.51 & 2484 \\
\hline C & 10.56 & 30.48 & 24.99 & 3.59 & 2367 \\
\hline D & 18.11 & 31.27 & 27.05 & 1.94 & 1024 \\
\hline
\end{tabular}

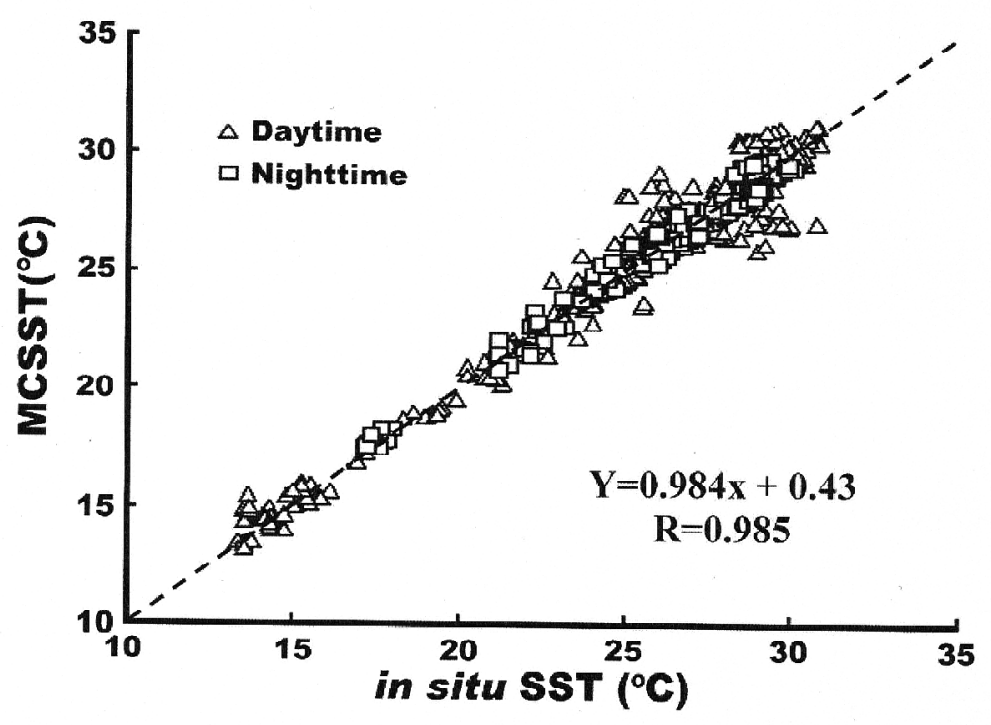

Fig. 5. Relationship between the MCSSTs and in situ SSTs. 


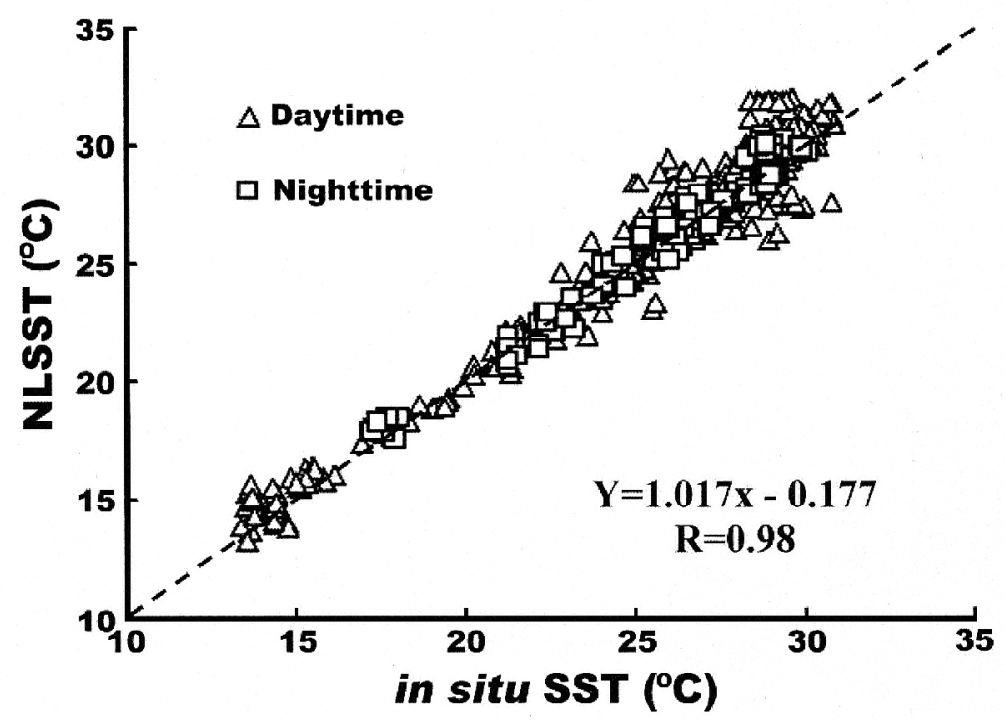

Fig. 6. Relationship between the NLSSTs and in situ SSTs.

Table 5. The root mean square deviation (RMSD, $\left.{ }^{\circ} \mathrm{C}\right)$ and bias $\left({ }^{\circ} \mathrm{C}\right)$ of the difference between the in situ SSTs and satellite derived-MCSST and NLSST.

\begin{tabular}{|c|c|c|c|c|c|}
\hline \multirow{2}{*}{ Time Algorithm } & \multicolumn{2}{|c|}{ MCSST } & \multicolumn{2}{c|}{ NLSST } & \multirow{2}{*}{ N } \\
\cline { 2 - 6 } & RMSD & Bias & RMSD & Bias & \\
\hline Daytime & 0.665 & 0.045 & 0.845 & 0.303 & 782 \\
\hline Nighttime & 0.522 & -0.147 & 0.573 & 0.051 & 179 \\
\hline Total & 0.640 & 0.009 & 0.801 & 0.256 & 961 \\
\hline
\end{tabular}

Figure 8 shows histograms of the differences between the MCSSTs/NLSSTs and the in situ SSTs. Most differences were distributed within $0.5 \mathrm{C}^{\circ}$ and constituted about $68 \%$ of the total samples. According to Fig. 8, the class from $0.15 \mathrm{C}^{\circ}$ to $0.75 \mathrm{C}^{\circ}$ had higher occurrence, producing the positive bias for the NLSSTs.

\section{DISCUSSIONS}

It is shown from our study that the AVHRR-derived SSTs using the MCSST and NLSST algorithms with the NOAA-provided coefficients were highly accurate in the waters around 

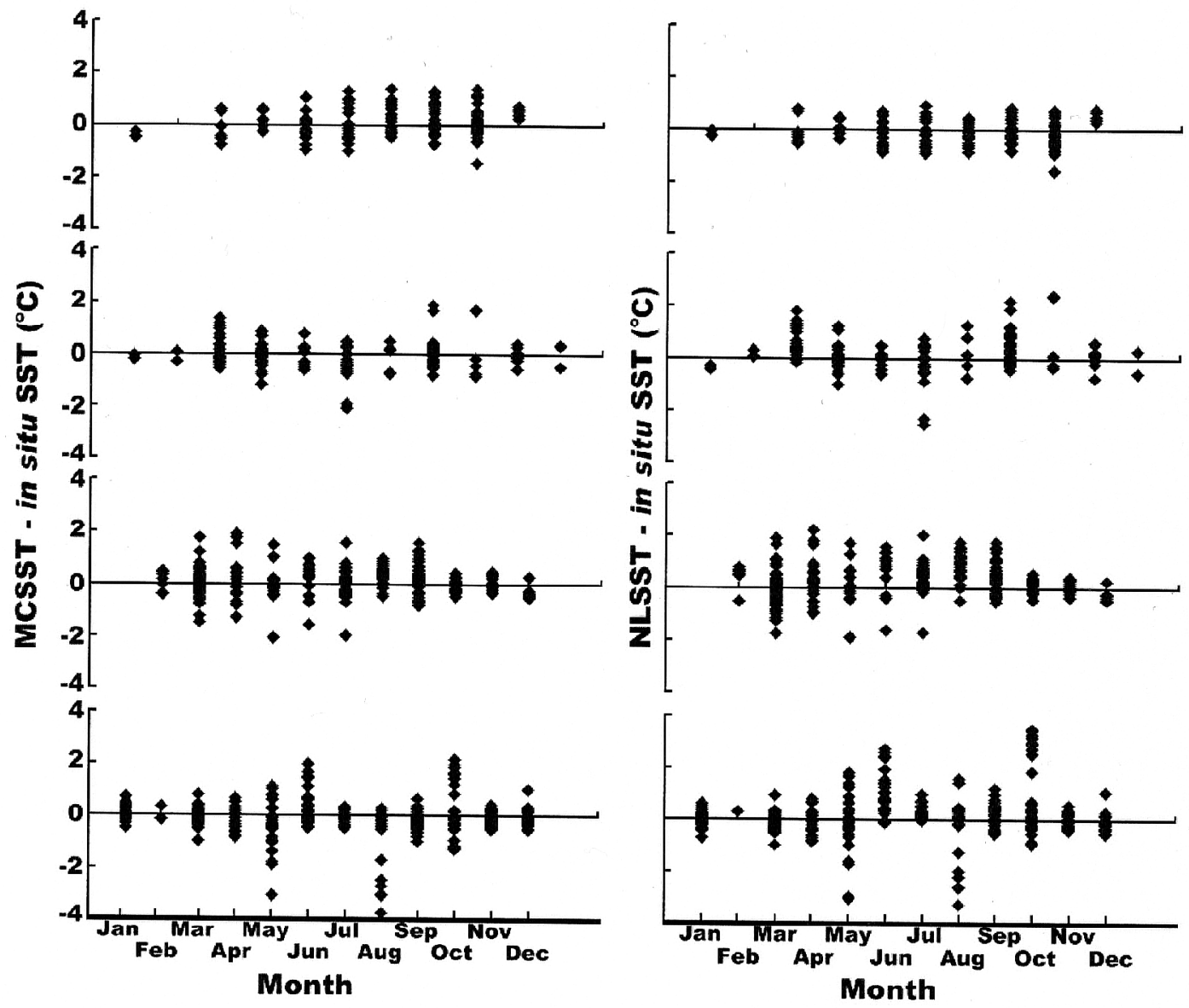

Fig. 7. The monthly time series of the difference between the NOAA MCSST (left)/NLSST(right) values and in situ SSTs in different temperature range at different areas. A D represents the respective subdivision shown in Fig. 1.

Taiwan. The accuracy is similar to that in the regional validations conducted in other areas (e.g., Sakaida and Kawamura 1992b; Barton and Skirving 1999). However, the bias and root mean square deviation (RMSD)of SST residuals estimated by the MCSSTs were better than those estimated by the NLSSTs. The NLSST algorithm is developed to improve the MCSST algorithm, and partly to improve cloud detection algorithms (Li et al. 2001). Since MCSST did agree well with the in situ SSTs in our study, the NLSST probably over corrected the MCSST. The validation of MCSST in general is through drift-buoy SSTs. The global mean satellitebuoy bias is less than $0.3 \mathrm{C}^{\circ}$ with an RMSD of about $0.7 \mathrm{C}^{\circ}$ ( $\mathrm{Li}$ et al. 2001). Our present study used all available in situ SSTs with depth of less than $5 \mathrm{~m}$ in the waters around Taiwan. The 


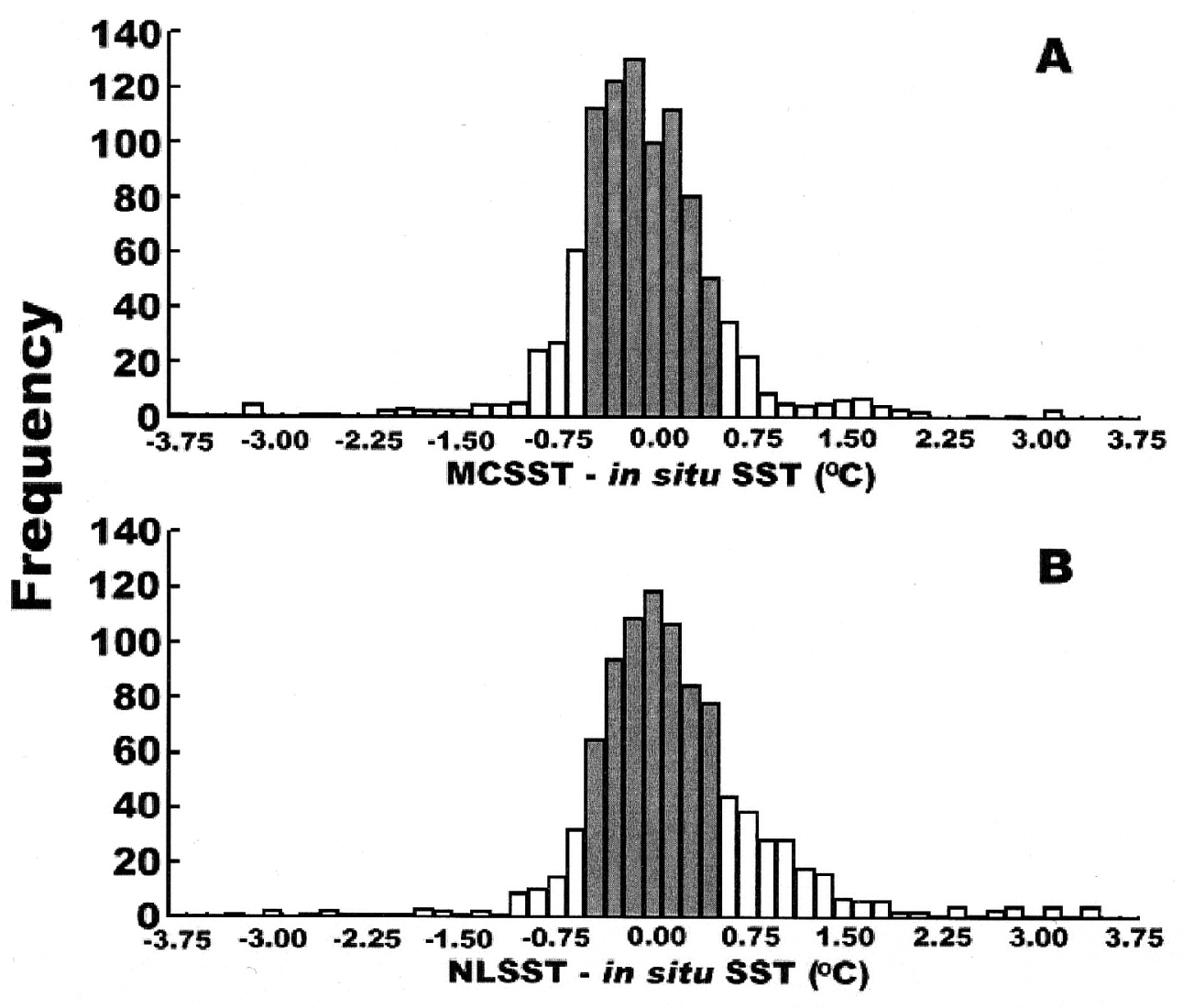

Fig. 8. Histograms of MCSST (a) and NLSST (b) estimation errors. Classes within the range of $-0.45 \mathrm{C}^{\circ}$ to $0.45 \mathrm{C}^{\circ}$ are shaded.

use of this data set might be one of the reasons why the regional NLSST results were worse. The present study is the first attempt to validate the AVHRR SST with the in situ data in the waters around Taiwan. Further observations should be followed to study SST physics with emphasis on regional characteristics. Examination of the depth effect on SST accuracy should be investigated in future studies. Casey and Cornillon (1999) also suggested that satellite SST retrieval might be degraded by contamination from thin or small clouds, which significantly reduces the estimated SSTs. In the present study, AVHRR match-up images around the in situ SST observation locations were checked by eye, and cloud contamination was carefully screened. However, the large deviation points $\left(<-3.0 \mathrm{C}^{\circ}\right)$ in the subdivision area $\mathrm{D}$ might be due to thin or small cloud contamination. In the case of sub-pixel sized clouds, it is quite difficult to screen all of the influenced AVHRR pixels even by eye. Fortunately, the number of large deviation points was limited and did not influence the statistics of the present validation. 
Problems associated with thin or sub-pixel clouds are also to be subjects of future study.

For area D (northern South China Sea) with the small mean standard deviation of $1.94 \mathrm{C}^{\circ}$ (Table 4), the differences between MCSSTs and in situ SSTs were larger during the period from May to September and sometimes exceeded $\pm 3 \mathrm{C}^{\circ}$ (Figs. 5, 7). There is a possibility that the MCSST algorithm may not correct atmospheric effects on SST retrieval (Sakaida and Kawamura 1992b). This is similar to that of Li et al (2001) who found a fairly large bias of about $1.5 \mathrm{C}^{\circ}$ in the summer months in the Great Lakes region. They indicated that there was often a uniform low-level fog over the lake surface. The fog was so thin and its temperature was so close to (but generally higher than) the lake surface temperature that the cloud test could not detect the presence of fog. In order to check this possibility, the differences (MCSSTs minus in situ SSTs) in daytime and nighttime were plotted against the differences between the brightness temperature of channel 4 and $5, T_{4}-T_{5}$ (Fig. 9). As a result, the SST differences distributed evenly around zero over a wide range of $\mathrm{T}_{4}-\mathrm{T}_{5}$ and no significant relationship existed between SST difference and $\mathrm{T}_{4}-\mathrm{T}_{5}$. It indicated that the match-up data were selected successfully and the atmospheric effects represented by $T_{4}-T_{5}$ were well corrected by the MCSST/NLSST algorithm. Another possibility is that spatial biases of SST existed in the waters around Taiwan. This is similar to that of Kawai and Kawamura (1997a) who discovered large-scale spatial biases in the regions north of $40^{\circ} \mathrm{N}$ and the Tsushima and in Tsugaru Warm Current regions. The biases varied with a seasonal cycle in the former region; the biases were negative in winter and positive in summer and the amplitude of the seasonal bias variation was more than $2 \mathrm{C}^{\circ}$. Price and Weller (1986) suggested that the difference between MCSST
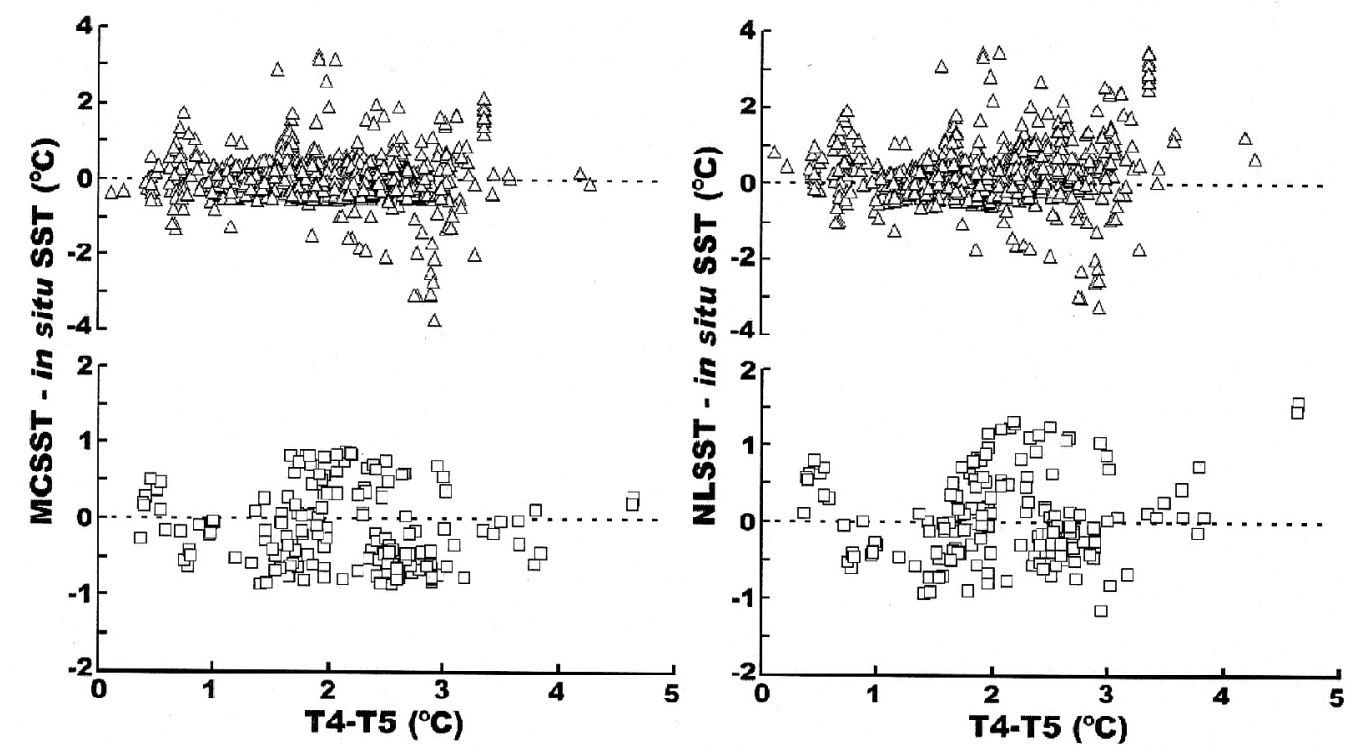

Fig. 9. The difference between MCSST(left), NLSST(right) and in situ SST versus $\mathrm{T}_{4}-\mathrm{T}_{5}$ in daytime (A) and nighttime (B). 
and in situ SST may be induced by the diurnal influence of solar radiation, which has a profound effect upon the velocity of wind-driven current (Kawai and Kawamura 1997b). In the simulation of the diurnal variation of sea surface temperature in a one-dimensional numerical model (Kawai and Kawamura 2002), the sea surface temperature became much lower than the in situ value as wind speed decreased. Because of this diurnal cooling, match-ups made within $4 \mathrm{hrs}$ should be considered in the future (Li et al. 2001).

What are the major sources of AVHRR-SST errors in this region? Stewart (1985) thought that surface heat flux might be a possible source. As shown in Fig. 7, large differences were mainly observed during the period from May to August when the southwestern monsoon prevails in this region. The seasonal mean SSTs in Fig. 4 demonstrate that the ocean was heated by local air-sea interactions. Differences in the SST fields between the open ocean and the continental shelf were enhanced in winter (mean SSTs) and spring (standard deviations). In addition to air temperature, the differences are affected by the southward flowing Coastal Cold Waters from the East China Sea during the winter NE monsoon from October to March (Lee et al. 2003; Jan et al. 2002). The sharp vertical gradient at the sea surface, formed in the heating period (e.g., Yokoyama et al. 1995; Kawai and Kawamura 2000; Donlon et al. 2002), is a source of deviation between the MCSSTs and the in situ SSTs. However, the in situ observations used in the present study did not have concurrent information on the near-surface vertical temperature structure and wind speed. Examination of the air-sea interaction effect should be investigated in the future.

\section{CONCLUSION}

Using locally-received AVHRR images of NOAA-12 16 and high quality CTD SST observations in the seas around Taiwan for the period of 1998 to 2002, we produced a match-up data set of 961 pairs, of AVHRR measurements and in situ SST. Availability of cloud-free images, i.e., images with cloud-free area exceeding $85 \%$ of their coverage area, was about $2.23 \%$ of all AVHRR images in the study period. The MCSST and NLSST algorithms with the NOAA-published coefficients for each NOAA satellite were examined in detail using a match-up data set. Although SST characteristics are different on the continental shelf and in the open ocean, the AVHRR-derived SSTs proved to be highly accurate. Relative to the in situ SSTs, the MCSSTs and NLSSTs had a bias (MCSSTs/NLSSTs minus in situ SST) of $0.009 \mathrm{C}^{\circ}$ and $0.256 \mathrm{C}^{\circ}$ with RMS deviations of $0.64 \mathrm{C}^{\circ}$ and $0.801 \mathrm{C}^{\circ}$, respectively. The differences between MCSSTs/NLSSTs and the in situ SSTs were distributed within $\pm 0.5 \mathrm{C}^{\circ}$ and they constituted about $68 \%$ of total samples.

Acknowledgement We would like to express our appreciation to the National Center for Ocean Research for providing the in situ data. The authors would like to thanks Prof. PingTung Shaw and Prof. Chang-Tai. Shih for their discussion on this manuscript and for the three anonymous referees who made constructive comments and valuable suggestions. The study is financially supported by the National Science Council (NSC 91-2119-M019-004) of the Republic of China (R.O.C), and is also supported by Special Coordination Fund for Promoting Science and Technology "New Generation SST" of MEXT, Japan. 


\section{REFERENCES}

Anding, D., and R. Kauth, 1970: Estimation of sea surface temperature from space. Remote Sens. Environ., 1, 217-220.

Bates, J. J., and H. F. Diaz, 1991: Evaluation of multichannel sea surface temperature product quality for climate monitoring: 1982-1988.J. Geophys. Res., 96, 613-20622.

Barton, L. J., 1995: Satellite-derived sea surface temperature: current status.J. Geophys. Res, 100, 8777-8790.

Barton, L. J., and W. J. Skirving, 1999: Satellite-derived sea surface temperature intercomparison: a case study. Adv. Space Res, 23, 1517-1523.

Bernstein, R. L., 1982: Sea surface temperature estimation using the NOAA 6 satellite advanced very high resolution radiometer. J. Geophys. Res., 87, 9455-9465.

Casey, K. S., and P. Cornillon, 1999: A comparison of satellite and in situ-based sea surface temperature climatologies. J. Climate, 12, 1848-1863.

Cho, H. J., and K. Matsuoka, 2001: Distribution of dinoflagellate cysts in surface sediments from the Yellow Sea and East China Sea. Mar. Micropaleont., 42, 103-123.

Donlon C. J., P. J. Minnett, C. Gentemann, T. J. Nightingale, I. J. Barton, B. Ward, and M. J. Murray, 2002: Toward improved validation of satellite sea surface skin temperature measurements for climate research. J. Climate, 15, 353-369.

Gong, G. C., C. Z. Shyu, W. H. Shin, and K. K. Liu, 1992: Temperature fluctuation of the cold water off northern Taiwan. Acta Oceanogr. Taiwanica, 28, 118-127.

Hu, J., H. Kawamura, H. Hong, and Y. Qi, 2000: A review on the currents in the South China Sea: seasonal circulation, South China Sea Warm Current and Kuroshio intrusion. J. Oceanogr., 56, 607-624.

Jan, S., J. Wang, C. S. Chern, and S. Y. Chao, 2002: Seasonal variation of the circulation in the Taiwan Strait. J. Mar. Sys., 35, 249-268.

Kawai, Y., and H. Kawamura, 1997a: Characteristics of the satellite-derived sea surface temperature in the oceans around Japan.J. Oceanogr., 53, 161-172.

Kawai, Y., and H. Kawamura, 1997b: Seasonal and diurnal variability of differences between satellite-derived and in situ sea surface temperatures in the south of the Sea of Okhotske. J. Oceanogr., 53, 343-354.

Kawai, Y., and H. Kawamura, 2000: Study on a platform effect in the in situ sea surface temperature observations under weak wind and clear sky conditions using numerical models. J. Atmos. Oceanic Technol., 17, 185-196.

Kawai, Y., and H. Kawamura, 2002: Evaluation of the diurnal warming of sea surface temperature using satellite-derived marine meteorological data.J. Oceanogr., 58, 805-814.

Key, J. R., B. C. Collins, C. Fowler, and R. S. Stone, 1997: High-latitude surface temperature estimates from thermal satellite data. Re. Sens. Environ., 61, 302-309.

Kubota, M., 1994: A new cloud detection algorithm for nighttime AVHRR/HRPT data.J. Oceangr., 50, 31-42.

Lee, M. A., J. R. Wang, T. J. Cheng, S. C. Chou, and K. T. Lee, 1999: A case study on the category composition and distribution of zooplankton in the sound scattering layer of offshore waters of north Taiwan. J. Fish. Soc. Taiwan, 26, 133-144. 
Lee, M. A., C. D. Yeah, C. H. Cheng, J. W. Chan, and K. T. Lee, 2003: Empirical orthogonal function analysis of AVHRR sea surface temperature patterns in Taiwan Strait.J. Mar. Sci. Technol., 11, 1-7.

Li, X., W. Pichel, P. Clemente-Colon, V. Krasnopolsky and J. Sapper, 2001: Validation of coastal sea and lake surface temperature measurements derived from NOAA/AVHRR data. Int. J. Remote Sens., 22, 1285-1303.

Lin, C. Y., C. Z. Shyu, and W. H. Shih, 1992: The kuroshio fronts and cold eddies off northeastern Taiwan observed by NOAA-AVHRR imageries. Terr. Atmos. Ocean. Sci., 3, 225-242.

Lin, F. J., S. C. Hsu, and W. L. Jeng, 2000: Lead in the Southern East China Sea. Mar. Environ. Res., 49, 329-342.

Liao, C. H., K. T. Lee, M. A. Lee, and H. J. Lu, 1997: Oceanographic Conditions and Surface Layer Biomass Distribution Characteristics in the Waters of Northern Taiwan.J. Fish. Soc. Taiwan, 24, 283-297.

McMillin, L. M., and D. S. Crosby, 1984: Theory and validation of the multiple window sea surface temperature technique. J. Geophys. Res., 89, 3655-3661.

McClain, E. P., W. G. Pichel, and C. C. Walton, 1985: Comparative performance of AVHRR based multichannel sea surface temperatures. J. Geophys. Res., 90, 11587-11601.

Sakaida, F., and H. Kawamura, 1992a: Accuracies of NOAA/NESDIS sea surface temperature estimation technique in the oceans around Japan. J. Oceanogr., 48, 345-351.

Sakaida, F., and H. Kawamura, 1992b: Estimation of sea surface temperature around Japan using the advanced very high resolution radiometer (AVHRR)/NOAA-11. J. Oceanogr., 48, 179-192.

Sakaida, F., and H. Kawamura, 1996: HIGHERS-The AVHRR-based higher spatial resolution sea surface temperature data set intended for studying the ocean south of Japan. J. Oceanogr., 52, 441-455.

Stewart, R. H.,1985: Methods of satellite oceanography. Univ. California Press, 260 pp.

Strong, A. E., and E. P. McClain, 1984: Improved ocean surface temperatures from spacecomparisons with drifting buoys. Bull. Am. Meteorol. Soc., 65, 138-142.

Walton, C., 1988: Nonlinear multichannel algorithms for estimating sea surface temperature with AVHRR satellite data. J. Appl. Meteor., 27, 115-124.

$\mathrm{Xu}, \mathrm{X}$., and M. Oda, 1999: Surface-water evolution of the eastern East China Sea during the last 36,000 years. Mar. Geol., 156, 285-304.

Yokoyama, R., S. Tanba, and T. Souma, 1995: Sea surface effects on the sea surface temperature estimation by remote sensing. Int. J. Remote Sens., 16, 227-238. 